\title{
Natural Frequency Analysis of a Jeffcott Rotor Having Stepped Shaft
}

\author{
Ahmed A. Alahmadi, Khalid A. Alnefaie, and Hamza Diken
}

\begin{abstract}
The Rotating shafts are mechanical elements used to transmit power or motion. A shaft with a step or steps is widely used instead of a shaft with a fixed (non-variable) diameter when operating at high speeds. The aim of this research is to study the effect of the step amount and its location in the shaft on the natural frequencies of the Jeffcott rotor model. Analytical methods are used to find an approximate formulation to obtain the natural frequencies of the Jeffcott rotor model neglecting the shaft mass. Lagrange equations are used to develop dynamic equations assuming elastic shaft with steps carrying a disk. The finite element method by using ANSYS is used to validate and compare the results obtained in the analytical method. The results obtained analytically and numerically were compatible and in good agreement. In addition, some parameters such as the step amount and the stepped shaft length are changed to check its effects on the natural frequencies. the results showed that the natural frequencies increase with an increase in the amount and length of the stepped part, while they decrease the closer the disc position to the center.
\end{abstract}

Index Terms - Analytical solution, Jeffcott Rotor, Natural Frequency, Stepped Shaft.

\section{INTRODUCTION}

Shafts can simply be defined as mechanical elements used to transmit power or motion. They also support and carry disk or gear type elements for different purposes. The rotor model to be discussed in this thesis consists of a shaft with a disc at is center or in different location. the shaft diameter may change in stepped manner and also the length of the stepped portion. In this case, the shaft is a solid cylinder on which various components are mounted. Mounted components on the shaft are often called disks and they are modeled as rigid objects due to their high stiffness when compared with the shaft. Therefore, only mass and inertia properties of the disks are important in the natural frequency analysis of the rotor. Shafts are flexible elements and also have mass and inertia. A complete specification of the shaft requires its geometric dimensions and material properties, such as Young's modulus, Poisson's ratio, and density. Bearings are the components on which the shaft is supported. These components are described by their equivalent stiffness and damping coefficients [2].

Rotating shafts are used in gas turbines, turbochargers, pumps, compressors, electric generators, and motors [2]. Modern rotating machinery operate at high speeds and the most extensive portion of the literature on the dynamics of

Submitted on April 09,2020.

Published on April 30, 2021.

Ahmed A. Alahmadi, King Abdulaziz University, Jeddah, Saudi Arabia.

(e-mail: aalahmadi0272@stu.kau.edu.sa). rotating shafts is concerned with determining critical speeds and natural frequencies [3].

In this paper, the effect of step amount and its length in the shaft will be investigated on the natural frequencies of the Jeffcott rotor model. Natural frequencies are obtained by using analytical method, approximate formulation, and Finite Element Method (ANSYS) and the results are compared.

\section{MethodolOGY}

Design a Jeffcott rotor model having a stepped shaft to analytically study the natural frequency that affected by the amount of step and the location of the disk. Finding the natural frequencies of the model considering the effect of the mass of the stepped shaft by using Euler-Bernoulli beam theory. The design of the model is simply supported beam which in left edge is a roller support and right edge is a pinned support and the location of the disk in the middle or any location in between Fig. 1.

Kinetic energy equation:

$$
\begin{aligned}
& T=\frac{1}{2} \int_{0}^{L} \rho A(x)(\dot{W}(x, t))^{2} d x+\frac{1}{2} \int_{0}^{L} m_{d}(\dot{W}(x, t))^{2} \delta(x- \\
& \text { a) } d x+\frac{1}{2} \int_{0}^{L} J_{d}\left(\dot{W}^{\prime}(x, t)\right)^{2} \delta(x-a) d x
\end{aligned}
$$

Potential energy equation:

$V=\frac{1}{2} \int_{0}^{L} E I(x)\left(W^{\prime \prime}(x, t)\right)^{2} d x$

The solution is assumed to be the sum of the orthogonal modes as:

$W(x, t)=\sum_{i=1}^{n} \Phi_{n}(x) q_{n}(t)$

The mode shape functions for simply supported beam is:

$\Phi_{n}=\sin \beta L=\sin n \pi$

Lagrange's equation can be expressed as:

$\frac{\partial L}{\partial q_{n}}-\frac{\partial}{\partial t}\left(\frac{\partial L}{\partial \dot{q}_{n}}\right)=0$

$\frac{\partial L}{\partial q_{i}}=-\left(\int_{0}^{L} E I(x) \Phi_{n}^{\prime \prime 2}(x) d x\right) \mathrm{q}_{n}$

Khalid A. Alnefaie, Mechanical Engineering Department, Faculty of Engineering, King Abdulaziz University, Saudi Arabia. Hamza Diken, Mechanical Engineering Department, Faculty of Engineering, King Abdulaziz University, Saudi Arabia. 
$\frac{\partial}{\partial t}\left(\frac{\partial L}{\partial \dot{q}_{i}}\right)=\left(\int_{0}^{L} \rho A(x) \Phi_{n}^{2}(x) d x\right) \ddot{\mathrm{q}}_{n}+\left(\int_{0}^{L} m_{d} \Phi_{n}^{2}(x) \delta(x-\right.$

a) $d x) \ddot{\mathrm{q}}_{n}+\left(\int_{0}^{L} J_{d} \Phi_{n}^{\prime 2}(x) \delta(x-a) d x\right) \ddot{\mathrm{q}}_{n}$

$\left[K_{n}\right]=\int_{0}^{L} E I(x) \Phi^{\prime \prime 2}(x) d x$

$\left[M_{n 1}\right]=\int_{0}^{L} \rho A(x) \Phi_{n}^{2}(x) d x$

$\left[M_{n 2}\right]=\int_{0}^{L} m_{d} \Phi_{n}^{2}(x) \delta(x-a) d x$

$\left[M_{n 3}\right]=\int_{0}^{L} J_{d} \Phi_{n}^{\prime 2}(x) \delta(x-a) d x$

$\left[M_{n}\right]=\left[M_{n 1}\right]+\left[M_{n 2}\right]+\left[M_{n 3}\right]$

A matrix in the form of $\left[M_{n}\right]\left\{\ddot{q}_{n}\right\}+\left[K_{n}\right]\left\{q_{n}\right\}=\{0\}$ Will be structured in MATLAB to obtain the natural frequency.

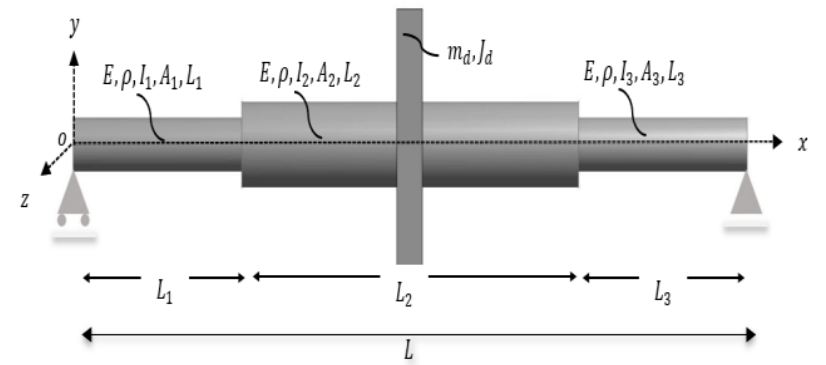

Fig. 1. A Jeffcott rotor model having a stepped shaft in xy plane.

Finite element method (FEM) one of the numerical methods to find the solution and ANSYS program will be used to investigate the natural frequencies of the Jeffcott rotor model having a stepped shaft which have varying step size and length. Also, the purpose of using the FEM is to compare results obtained in the analytical approach. The ANSYS solution will deal with the model as a simply supported stepped shaft with single disk. The stepped shaft and disk are assumed to be steel with Young's modulus of $200 \mathrm{GPa}$ with a density of $7850 \mathrm{~kg} / \mathrm{m}^{3}$. The thickness of the disk is $15 \mathrm{~mm}$ and the length of stepped shaft is $1000 \mathrm{~mm}$. The mesh element is selected to be SOLID186 with a size of $7 \mathrm{~mm}$ which can be defined is a higher order 3-D axisymmetric with 20-node. so, the mesh is created of 10011 elements and of 50728 nodes. Other parameters such as diameter of stepped shaft, the length of stepped shaft and location of disk are considered as variables.

\section{RESULTS AND DISCUSSION}

Simulations are undertaken to compare the numerical results with those obtained from the analytical models. In the first simulation, changing the diameter of the stepped shaft with keeping the location of the disk on the middle and keeping the length of the stepped shaft as $500 \mathrm{~mm}$. In the second simulation, stepped part of the shaft length is changed keeping the diameter of the stepped shaft is unchanged as 58 $\mathrm{mm}$, and the disk is in the middle. In the last simulation, different locations of the disk are used to assess the effects of disk location on the natural frequencies.

\section{A. Changing the Diameter of the Stepped Shaft}

Diameter of the stepped shaft is changing from 50 to 59 $\mathrm{mm}$. The analytical model results match with the finite element method results very well in the first and third frequencies and well in the second frequency (Table I).

TABLE I: NATURAL FREQUENCIES OBTAINED FROM THE EULER BEAM MODEL AND ANSYS FOR DIFFERENT DIAMETERS OF THE ONE STEP SHAFT

\begin{tabular}{cccc}
\hline \multicolumn{4}{c}{$D_{1}=50 \mathrm{~mm}$} \\
\hline Mode & Euler beam $(\mathrm{Hz})$ & ANSYS $(\mathrm{Hz})$ & Error $(\%)$ \\
\hline 1 & 74.83 & 75.83 & 1.32 \\
2 & 395.28 & 367.51 & 7.55 \\
3 & 747.13 & 731.30 & 2.17 \\
\hline \multicolumn{4}{c}{$D_{1}=55 \mathrm{~mm}$} \\
\hline 1 & 83.88 & 84.37 & 0.58 \\
2 & 417.50 & 386.38 & 8.05 \\
3 & 782.58 & 777.15 & 0.70 \\
\hline \multicolumn{4}{c}{$D_{1}=59 \mathrm{~mm}$} \\
\hline 1 & 91.48 & 90.33 \\
3 & 438.30 & 395.69 & 1.27 \\
\hline \hline
\end{tabular}

\section{B. Changing the Length of the Stepped Shaft}

Length of the stepped shaft is changing from $500 \mathrm{~mm}$ to $800 \mathrm{~mm}$. The natural frequency results of the analytical models and numerical (ANSYS) model results agree very well in the first frequency and third frequencies. Second frequency results are relatively well (Table II).

TABLE II: NATURAL FREQUENCIES OBTAINED FROM THE EULER BEAM METHOD AND THE ANSYS FOR DIFFERENT LENGTHS OF THE ONE STEP SHAFT

\begin{tabular}{cccc}
\hline \hline \multicolumn{4}{c}{$L_{1}=500 \mathrm{~mm}$} \\
\hline Mode & Euler beam $(\mathrm{Hz})$ & ANSYS $(\mathrm{Hz})$ & Error $(\%)$ \\
\hline 1 & 89.55 & 88.98 & 0.64 \\
2 & 432.88 & 393.81 & 9.92 \\
3 & 808.46 & 803.14 & 0.66 \\
\hline \multicolumn{4}{c}{$L_{1}=600 \mathrm{~mm}$} \\
\hline 1 & 90.74 & 90.88 & 0.15 \\
2 & 443.98 & 406.09 & 9.33 \\
3 & 829.64 & 809.39 & 2.50 \\
\hline \multicolumn{4}{c}{$L_{1}=800 \mathrm{~mm}$} \\
\hline 1 & 91.88 & 92.89 & 1.09 \\
3 & 456.69 & 426.45 & 7.09 \\
\hline \hline
\end{tabular}

\section{Changing the Location of the Disk}

The location of the disk changes from $500 \mathrm{~mm}$ to $700 \mathrm{~mm}$. The first natural frequency rise can be observed when the disc position changes from the middle to any left and right position in the shaft, because the highest deflection value is in the middle, which is the lowest value of the first frequency being in the middle, and the second and third natural frequency decreases when the disc position changes from the middle (Table III). 
TABLE III: NATURAL FREQUENCIES OBTAINED FROM THE EULER BEAM METHOD AND THE ANSYS FOR DIFFERENT POSITIONS OF THE DISC

\begin{tabular}{cccc}
\hline \hline \multicolumn{4}{c}{$L_{1}=500 \mathrm{~mm}$} \\
\hline Mode & Euler beam $(\mathrm{Hz})$ & ANSYS $(\mathrm{Hz})$ & Error $(\%)$ \\
\hline 1 & 89.55 & 88.98 & 0.64 \\
2 & 432.88 & 393.81 & 9.92 \\
3 & 808.46 & 803.14 & 0.66 \\
\hline \multicolumn{4}{c}{$L_{1}=600 \mathrm{~mm}$} \\
\hline 1 & 90.74 & 90.88 & 0.15 \\
2 & 443.98 & 406.09 & 9.33 \\
3 & 829.64 & 809.39 & 2.50 \\
\hline \multicolumn{4}{c}{$L_{1}=800 \mathrm{~mm}$} \\
\hline 1 & 91.88 & 92.89 \\
3 & 456.69 & 426.45 & 7.09 \\
\hline \hline
\end{tabular}

\section{CONCLUSION}

The aim of this thesis is to study the effect of step magnitude, length of the stepped part of the shaft and the position of the disk on the shaft on the natural frequencies of the Jeffcott rotor model. A study was conducted to investigate the effect of the step and stepped shaft length on the natural frequencies. Therefore, the following conclusion can be drawn from this study:

- Natural frequencies increase with increasing step amount.

- The natural frequencies increase with the increase in the stepped shaft length.

- First natural frequencies increase when the location of the disk is away from the centre but second and third natural frequencies are decreasing.

Although the analyses and methodologies presented are good enough to designate a robust tool for investigating natural frequencies, some improvements can still be made through the use and development of other analytical methods and also their real-world study and improvement of their results. The effect of step magnitude, stepped length and the position of the disk on the shaft of the Jeffcott rotor model can be studied in other forms and comparison of natural frequency results can be made, for example:

- Cantilevered Jeffcott rotor.

- Overhanging Jeffcott rotor.

\section{REFERENCES}

[1] Dynamics of Rotors and Foundations by Erwin Kramer (1993) published by Springer-Verlag Berlin Heidelberg GmbH (pp.4-44).

[2] https://www.comsol.com/blogs/analyzing-critical-speeds-with-therotor-bearing-system- simulator/.

[3] Dynamics of Rotating Shafts by Robert G Loewry, Vincent J Piarulli (1969) (pp. 5-20). 